\title{
MÍDIA, CULTURA DE PAZ E EDUCAÇÃO FÍSICA ESCOLAR
}

MEDIOS, CULTURA DE PAZ Y EDUCACIÓN FÍSICA ESCOLAR

MEDIA, PEACE CULTURE AND SCHOOL PHYSICAL EDUCATION

\author{
Giseli Fregolente PATRINHANI ${ }^{1}$ \\ Marcos AMÉRICO ${ }^{2}$
}

RESUMO: Ao observar o cotidiano escolar é possível verificar a grande influência midiática no comportamento dos alunos, chamando a atenção ao fato de que exercem papel fundamental no contexto de reprodução e propagação de violências. Cabe à instituição escolar lidar com esses conflitos e promover situações de aprendizagens voltadas para a propagação de uma cultura de paz. Este artigo traz reflexões sobre essas questões e relato de uma intervenção realizada com alunos do ensino fundamental II de uma escola pública estadual durante as aulas de Educação Física. A inspiração veio da concepção filosófica e a proposta metodológica de Paulo Freire. Foi detectada a necessidade de se pensar em uma comunicação que não se resuma somente a contar os fatos ocorridos, mas que analise as causas, promova espaços de reflexões, proponha soluções, contribuindo para uma transformação em nossa sociedade.

PALAVRAS-CHAVE: Cultura de paz. Educação física escolar. Mídia e tecnologia. Práticas pedagógicas.

RESUMEN: Al observar la rutina escolar, es posible verificar la gran influencia de los medios en el comportamiento de los estudiantes, llamando la atención sobre el hecho de que juegan un papel fundamental en el contexto de la reproducción y propagación de la violencia. Corresponde a la institución escolar lidiar con estos conflictos y promover situaciones de aprendizaje dirigidas a la propagación de una cultura de paz. Este artículo trae reflexiones sobre estos temas e informes sobre una intervención realizada con estudiantes de primaria de una escuela pública estatal durante las clases de Educación Física. La inspiración vino de la concepción filosófica y la propuesta metodológica de Paulo Freire. Se detectó la necesidad de pensar en una comunicación que no se limite a contar los hechos, sino que analice las causas, promueva espacios para reflexionar, proponga soluciones, contribuyendo a una transformación en nuestra sociedad.

PALABRAS CLAVE: Cultura de paz. Educación física escolar. Medios y tecnología. Prácticas pedagógicas.

\footnotetext{
${ }^{1}$ Universidade Estadual Paulista (UNESP), Bauru - SP - Brasil. Doutoranda no Programa de Pós-Graduação em Mídia e Tecnologia. e PEB II efetiva - Secretaria da Educação do Estado de SP. ORCID: https://orcid.org/00000002-5819-6996. E-mail: giseli.fregolente@unesp.br

${ }^{2}$ Universidade Estadual Paulista (UNESP), Bauru - SP - Brasil. Docente e Coordenador do Programa de PósGraduação em Mídia e Tecnologia. ORCID: https://orcid.org/0000-0001-7920-4513. E-mail: marcos.americo@unesp.br
} 
ABSTRACT: When observing the school daily life, it is possible to verify the great influence of the media in the behavior of the students, drawing attention to the fact that they play a fundamental role in the context of the reproduction and propagation of violence. It is up to the school to deal with these conflicts and promote learning situations aimed at the propagation of a culture of peace. This article reflects on these issues and reports of an intervention carried out with elementary school students from a state public school during Physical Education classes. The inspiration came from the philosophical conception and the methodological proposal of Paulo Freire. It was detected the need to think about a communication that does not only summarize the facts, but also analyzes the causes, promotes spaces for reflection, proposes solutions and contributes to a transformation in our society.

KEYWORDS: Culture of peace. School physical education. Media and technology. Medagogical practices.

\section{Introdução}

Ao observar o cotidiano escolar é possível verificar a grande influência midiática no comportamento dos alunos, onde, a partir de experiências particulares na área de Educação Física Escolar, podemos citar como exemplo os alunos com o mesmo penteado de alguns famosos jogadores de futebol, os quais tentam imitar também, nos jogos dentro da escola, o comportamento agressivo desses jogadores, visto por eles através da mídia. Isso nos leva a pensar de que maneira contribui para legitimar determinados tipos de violência. Essa violência exposta nos meios midiáticos, que mostra violências diretas advindas de violências estruturais e culturais, como especifica Galtung (2003), as quais influenciam diretamente o ambiente escolar estão se tornando cada vez mais uma grande preocupação para a escola, consequentemente, levando-nos a pensar em como a escola pode contribuir para a desconstrução dessa violência que vem a ser muito facilitada e divulgada. Sendo assim, foi pensado e proposto este estudo, com a finalidade de fazer reflexões e provocar inquietações sobre esse contexto, promovendo uma intervenção no ambiente escolar. Inicialmente, para ampliar o universo conceitual, foi realizada uma pesquisa bibliográfica sobre as temáticas relacionadas à violência, cultura de paz, comunicação para a paz, práticas pedagógicas dialogadas e midiatizadas.

Galtung (2003) elenca três tipos de violência: a violência direta, onde ocorre um ato de violência em si, concreto, onde sabemos quem é o agressor e agredido; a violência estrutural, resultado das desigualdades e injustiças sociais; e a violência cultural, que se apoia nas regras e comportamentos legitimados pela sociedade. Diferenciando-as temporalmente, o autor explica que a violência direta é um acontecimento, a violência estrutural é um processo e a 
violência cultural é uma constante. Segundo Galtung (2003), o objetivo de uma investigação para a paz é conhecer o contexto, as circunstâncias e analisar como se pode modificá-la.

Segundo o artigo $1^{\circ}$ da Resolução A/RES/53/243 de 1999 da Assembleia Geral das Nações Unidas (AGNU, 1999, p. 2-3):

Uma Cultura de Paz é um conjunto de valores, atitudes, tradições, comportamentos e estilos de vida baseados: a) No respeito à vida, no fim da violência e na promoção e prática da não-violência por meio da educação, do diálogo e da cooperação; b) No pleno respeito aos princípios de soberania, integridade territorial e independência política dos Estados e de não ingerência nos assuntos que são, essencialmente, de jurisdição interna dos Estados, em conformidade com a Carta das Nações Unidas e o direito internacional; c) No pleno respeito e na promoção de todos os direitos humanos e liberdades fundamentais; d) No compromisso com a solução pacífica dos conflitos; e) Nos esforços para satisfazer as necessidades de desenvolvimento e proteção do meio-ambiente para as gerações presente e futuras; f) No respeito e promoção do direito ao desenvolvimento; g) No respeito e fomento à igualdade de direitos e oportunidades de mulheres e homens; h) No respeito e fomento ao direito de todas as pessoas à liberdade de expressão, opinião e informação; i) Na adesão aos princípios de liberdade, justiça, democracia, tolerância, solidariedade, cooperação, pluralismo, diversidade cultural, diálogo e entendimento em todos os níveis da sociedade e entre as nações; e animados por uma atmosfera nacional e internacional que favoreça a paz.

A Resolução ainda complementa no artigo $3^{\circ}$ que:

O desenvolvimento pleno de uma Cultura de Paz está integralmente vinculado: a) À promoção da resolução pacífica dos conflitos, do respeito e entendimento mútuos e da cooperação internacional; b) Ao cumprimento das obrigações internacionais assumidas na Carta das Nações Unidas e ao direito internacional; c) À promoção da democracia, do desenvolvimento dos direitos humanos e das liberdades fundamentais e ao seu respectivo respeito e cumprimento; d) À possibilidade de que todas as pessoas, em todos os níveis, desenvolvam aptidões para o diálogo, negociação, formação de consenso e solução pacífica de controvérsias; e) Ao fortalecimento das instituições democráticas e à garantia de participação plena no processo de desenvolvimento; f) À erradicação da pobreza e do analfabetismo, e à redução das desigualdades entre as nações e dentro delas; g) À promoção do desenvolvimento econômico e social sustentável; h) À eliminação de todas as formas de discriminação contra a mulher, promovendo sua autonomia e uma representação eqüitativa em todos os níveis nas tomadas de decisões; i) Ao respeito, promoção e proteção dos direitos da criança; j) À garantia de livre circulação de informação em todos os níveis e promoção do acesso a ela; k) Ao aumento da transparência na prestação de contas na gestão dos assuntos públicos; 1) À eliminação de todas as formas de racismo, discriminação racial, xenofobia e intolerância correlatas; m) À promoção da compreensão, da tolerância e da solidariedade entre todas as civilizações, povos e culturas, inclusive relação às minorias étnicas, religiosas e lingüísticas; n) Ao pleno respeito ao direito de livre determinação de todos os povos, incluídos os que vivem sob dominação colonial ou outras formas 
de dominação ou ocupação estrangeira, como está consagrado na Carta das Nações Unidas e expresso nos Pactos internacionais de direitos humanos, bem como na Declaração sobre a concessão da independência aos países e povos colonizados contida na resolução 1514 (XV) da Assembléia Geral, de 14 de dezembro de 1960 (AGNU, 1999, p. 3-4).

Acreditamos que a questão chave seja estimular reflexões sobre o sofrimento humano, desenvolver uma consciência esclarecida sobre a possibilidade de ação de todo ser humano sobre esse sofrimento, o que podemos fazer uns aos outros e a nós mesmos, e a importância de se buscar alternativas pacíficas para resolução desses problemas, destes conflitos inerentes às próprias ações humanas, e o mais importante disso tudo, encontrar o sentido dessas ações, compreendê-las, refletir sobre elas, pois o sofrimento humano é inevitável mas há de se tirar algo de bom disso, servindo como um bom aprendizado para a vida. Martínez Guzmán (2010) aponta a dominação, a submissão e a exclusão como algumas causas do sofrimento humano. Ele comenta que a ideologia de pensar que não há o que ser feito, que o ser humano é por si só destrutivo, só dá forças maiores a essas causas. A questão primordial é reconhecer que realmente temos capacidade para gerar todo esse sofrimento, mas também temos capacidade de nos organizar ao oposto, promovendo pacificidade entre nossos pares. Partindo do pressuposto de que o ser humano se forma, se constitui humano, cria sua identidade no decorrer de suas interações com o mundo (com a natureza, com outras pessoas, com grupos de pensamentos diferentes, etc.), somos, nesse interim, seres inacabados, que estamos sempre em processo de construção, então há sempre esperança de novas possibilidades.

Quando elevamos nossos níveis de compreensão em relação aos demais também elevamos nossos valores humanos, como por exemplo nossa capacidade de perdoar e de se relacionar. Um trabalho reforçando valores humanos pode ser feito em qualquer idade, é uma formação para toda a vida, onde há a necessidade da inclusão dessa temática também na formação de professores nas universidades. Devemos promover valores humanos que conduzem a uma cultura de paz (FONTELES; GARCÍA, 2012).

Martínez Guzmán (2010, p. 29) frisa que:

[...] não é, portanto, a paz que se entende como a alternativa à violência - os diferentes tipos de violência é que supõem a ruptura da diversidade de formas de viver em paz com as quais configuramos originariamente as nossas relações enquanto seres humanos. A sensação de que a violência é que é o elemento primário vem de estar-se a pensar numa paz em termos absolutos, perfeita. Na realidade, esta paz absoluta e perfeita converte-se numa forma totalitária de dominação porque exclui a diversidade de saberes de acordo com os quais os seres humanos podem organizar as suas formas de vida de maneira pacífica. 
Sendo assim, é preciso romper com o estigma de pensar na paz a partir da violência, mas sim entender a paz como ela mesma um processo de estudo e permanente construção, fazendo ela parte dos elementos que constituem ações presentes nas relações humanas. Mas como podemos utilizar a mídia e a tecnologia como nossos aliados como meios para atingir esses fins dentro do ambiente escolar?

Para Rabbani (2010), implica, para um pleno exercício da cidadania em prol de uma sociedade mais justa, oportunizar espaços de diálogo a todos, não um simples diálogo, mas sim um espaço sincero, que valorize os sentimentos alheios e seja desprendido de verdades absolutas. Segundo Conte, Habowski e Rios (2019), a escola tem um importante papel no desenvolvimento de um trabalho visando uma leitura crítica perante as mídias e tecnologias, buscando um combate ao consumo superficial de informações, e o diálogo entre seus pares facilita essa leitura de mundo, buscando uma construção coletiva do conhecimento, como também defende Freire $(2000 ; 2007)$.

Fisas (1998) ressalta a grande influência exercida pelos meios de comunicação no nosso imaginário, principalmente nas crianças, que estão em processo de formação, e que apresentam uma extrema exposição à violência presentes nos diversos meios de comunicação, sendo a TV o principal meio, assim como muitos jogos de videogames. Os meios de comunicação de massa têm o poder de promover a violência para toda a sociedade, promovendo passividade e falta de senso crítico. Mas o autor também aponta que da mesma maneira que ela pode promover a violência, também pode agir no sentido contrário, promover a criação de uma cultura de paz. Portanto:

[...] los medios de comunicación tienden a dramatizar y a presentar el mundo de hoy como una sucesión de desastres y violencias imposibles de entender, y sobre los que nada puede hacerse. Sin embargo, necesitamos imperiosamente no solo que los medios actúen como intérpretes educativos de esa realidad que es ciertamente compleja, sino también como actores de primera línea en la tarea de crear una cultura de "estar juntos" a nivel planetario, y de educar para una acción de justicia (FISAS, 1998, p. 10).

Fisas (1998) frisa a importância de obtermos a capacidade de avaliar as informações que nos são ofertadas pelos diversos meios de comunicação, pois a mídia tem o poder de dissuadir-nos, manipular a informação para atender determinados interesses, dificultando um possível processo de melhor entendimento do contexto para resolução de conflitos. Entretanto, uma educação para a paz deve percorrer um caminho de busca por informações fidedignas, que valorizem as fontes diretas e que permitam uma interpretação correta da realidade. Nesse interim: 
La "naturalización de la violencia" es una realidad en muchas democracias contemporáneas que están sufriendo una auténtica ola de violencia, y en las que no sabemos exactamente qué hacer, probablemente por la multiplicidad de sus causas. [...] Es evidente, por todo ello, que la educación para la paz, además de ser una educación sobre los conflictos, ha de ser también una educación para la comprensión de los mecanismos de dominación y sumisión, y no sólo los estructurales, sino también los subliminales (FISAS, 1998, p. 17).

A escola, principalmente os professores, ao nosso ver, tem uma grande responsabilidade nesse contexto, podendo, através da sua atuação profissional, agir qualitativamente nessa realidade, contribuindo para uma mudança nesse paradigma. Segundo Silva (2010, p. 176):

O educador precisa perceber-se como um trabalhador para a paz, alguém que através do exercício de sua profissão valoriza o ser humano, acredita que todos têm potencialidades a desenvolver e que, através da educação, novas concepções e atitudes podem ser construídas.

O educador deve ser primeiramente um exemplo para seus educandos. De acordo com Menezes (2010, p. 187):

As funções do educador para a paz exigem que ele saiba atuar como coordenador de atividades em grupo, motivador de pesquisas e multiplicador de experiências; que ele seja autêntico e confiável e, evidentemente, que confie em seu próprio potencial; que ele seja pluralista e suficientemente aberto à diferença e à diversidade, além de cooperativo e previdente.

Libâneo (2002) comenta que, perante nossa sociedade, repleta de novas tecnologias da comunicação e informação, os educadores necessitam prestar atenção nas mídias, no papel que ela vem desempenhando e como fazer uso delas em sala de aula, no sentido de transformarem-se em consumidores críticos das mídias para contribuírem numa formação de educandos que também possam relacionar-se criticamente com as mídias. Segundo Libâneo (2002, p. 168), para ir "contra uma ideia linear e mecânica sobre o uso das mídias", professores e alunos precisam elaborar e transformar "ideias, sentimentos, atitudes, valores, utilizando articuladamente múltiplas mídias, escolares e não-escolares”. Para Libâneo (2002, p. 165), a informação por si só não propicia o conhecimento, ela é um meio para se chegar ao conhecimento, "ela precisa ser analisada, interpretada, retrabalhada". Ele ainda nos ilumina que "podemos resistir ao domínio da informação, à colonização da informação, pelo conhecimento, pelo pensamento". Assim, ele aponta que a educação e as escolas exercem um 
papel insubstituível de dar condições intelectuais para uma avaliação crítica "das condições de produção e da difusão do saber científico e da informação" (p. 166).

Como dizem Guareschi e Biz (2005, p. 40), “a Internet pode dar todas as respostas, mas não consegue fazer a pergunta". Os autores explicam que, das mídias, "o público recebe informações curtas, em fragmentos, sem uma contextualização ou um fio condutor” (p. 116). Para sair de uma postura passiva, de hipnose, para buscar reflexões críticas se faz necessário questionar o que lhe é dado. A escola, na figura do educador, pode contribuir nesse processo de conscientização, onde, segundo os autores, "o papel do educador não é dar respostas, mas sim fazer a pergunta, uma pergunta que liberta" (p. 22).

Betti (2003) chama a atenção que não é habitual pensarmos a educação envolta num processo de comunicação, pensamos nela como transmissão de conteúdos. No entanto, para existir comunicação é necessária uma interlocução entre pessoas, um diálogo, sendo assim, educação é um constante processo de comunicação, consequentemente, devemos pensar em como dinamizar esse processo de comunicação, havendo a possibilidade de utilizar diversos meios, dos mais tradicionais até os mais midiatizados.

O professor não pode deixar de fazer uso da grande quantidade de informações que existem em diversos meios midiáticos e tecnológicos, que muitas vezes são de fácil acesso e onde existem materiais atualizados que podem servir como recursos para fins educacionais. Para isso, é necessário que o professor busque atualização e adquira habilidades essenciais para uma prática pedagógica inovadora e criativa, assumindo também a responsabilidade de ser o mediador/facilitador entre os alunos e a tecnologia. O elemento fundamental do processo educativo é a comunicação entre professores e alunos, a tecnologia então vem a ser um meio para fins de resolução de problemas e aperfeiçoamento pedagógico (PÚBLIO JÚNIOR, 2018).

Pensando em uma prática pedagógica, em como atuar no contexto escolar em prol de uma educação voltada para uma cultura de paz aliando os recursos midiáticos e tecnológicos de uma maneira crítica, foi planejada uma proposta e aplicada, a qual será relatada a seguir.

\section{A intervenção}

Para a intervenção na escola, foi atribuído à mídia e à tecnologia papéis de facilitadores/recursos para embasar discussões críticas nas aulas. A metodologia de roda de conversa vem a se encaixar em nosso ideal, pois promove troca de informações, reflexões e estimula conscientização. Os professores vêm a assumir aqui o papel de facilitadores, pois os 
próprios indivíduos vão produzir uma visão de mundo dessa questão. A inspiração veio da concepção filosófica e a proposta metodológica de Paulo Freire $(2000 ; 2007)$, baseando-se na dialogicidade, a fim de compreender o contexto, sendo esse o ponto de partida para a descodificação, superar o senso comum para elaborar e descobrir novos significados, onde educador e educandos são atores em todo o processo educativo, valorizando a participação e contribuição de todos os envolvidos, sendo assim, através do processo de comunicação entre seus pares, encaminha-se para uma tomada de consciência rumo à construção da sua autonomia e emancipação.

A intervenção foi realizada durante as aulas do componente curricular Educação Física, com três turmas contendo cada uma por volta de trinta alunos ( $8^{\circ}$ ano $\mathrm{A}, \mathrm{B}$ e C) de uma escola pública estadual da cidade de Bauru/SP/Brasil, ao final do $1^{\circ}$ semestre de aulas do ano de 2018, em dois encontros antes do início das férias escolares. Para a intervenção, foram propostas as seguintes situações de aprendizagem:

Para iniciar, foi feito um levantamento prévio com os alunos sobre o que eles entendiam por violência no esporte e o que seria uma cultura de paz. Após as discussões na roda de conversa, com a mediação da professora, foi-se especificando e refletindo sobre a questão da violência no esporte, fazendo uma introdução expositiva sobre os tipos de violência (direta, estrutural e cultural), dando exemplos do cotidiano, alertando os educandos sobre os problemas relacionados à violência presentes nos diversos meios de comunicação (jornais, revistas, TV, internet, entre outros), assim como também foi explicado o que seria uma cultura de paz. Para servir como registro e avaliação, ao longo da intervenção, foi solicitado para que grupos de alunos fossem anotando algumas considerações sobre nossas discussões em aula, assim como também a professora relatava as aulas em diários, os quais também serviram como fonte direta para este presente artigo. Segue abaixo um resumo das rodas de conversa:

Quando questionados sobre o que seria violência no esporte, os alunos comentaram sobre agressões físicas e verbais no futebol, tanto entre atletas como entre torcedores, e sobre violência ser algo ruim. Muitos citaram exemplos de sua própria realidade na escola, onde ocorre muitas brigas nos jogos de futebol dentro da escola, como também citaram ver nos jogos de futebol na TV. Somente duas alunas citaram os esportes de luta que veem na TV, criticando-os, comentando que são muito violentos e há sangue, se referindo ao esporte MMA (Artes Marciais Mistas). Também uma aluna citou exemplo de violência na escola no jogo de queimada e uma aluna citou sobre brigas nas brincadeiras das crianças na rua. Comentaram sobre o problema vir do comportamento das pessoas, da questão de que muitos não sabem 
lidar com a derrota no jogo, "falta de espírito esportivo", pressão por resultados, citaram também "fofocas", "inveja", "vingança" e excesso de competitividade. Houve discussões sobre isso ser genético ou cultural.

Foi apontado como solução ter mais policiamento, dar punições, pedir perdão, ter árbitros que apitam bem o jogo e orientar as pessoas a não "zoar" os outros quando perdem, as pessoas devem ter mais respeito, saber ganhar e perder, entender que o importante é a participação, acreditam que deva ter mais conversas sobre os acontecimentos para conscientizar as pessoas sobre o prejuízo que isso causa, buscar ajuda com profissionais como psicólogos ou fazer atividades mais relaxantes como ioga, por exemplo, para ajudar as pessoas a se controlarem. Chamou atenção alguns registros de alunos do $8^{\circ}$ ano $\mathrm{A}$ :

Acho que isso acontece quando a pessoa tem uma criação agressiva e pode se solucionar com os pais sendo menos agressivos com os filhos.

Surge por alguém quando quebra uma regra ou por causa da pressão. Para evitar é só respeitar as regras.

Eu acho que esse problema é uma coisa que vem da criação da pessoa, se uma pessoa é criada em um lugar violento, ela vai ser violenta.

Quando questionados sobre o que seria uma cultura de paz, a maioria dos alunos disse que não sabia o que era, que nunca ouviram falar, mas poucos alunos fizeram considerações como: "não ter brigas", "todo mundo se entende", "onde existe conversa", "pessoas que não gostam de violência", "manter a paz sempre", "é o contrário das brigas, é harmonia, convivência, humor, capacidade, etc.", e "nunca ouvi falar, essa palavra é diferente, mas deve ser algo bom". Essa constatação da falta de conhecimento relacionado à cultura de paz já é um indício de que nossa sociedade está deixando muito a desejar sobre essa temática, que vem a ser muito importante nos dias de hoje, e que infelizmente o acesso sobre a violência está se sobressaindo, e o ponto mais crucial, sem fazer uma relação com ações voltadas para análises críticas e resoluções sobre isso.

Em seguida, para a aula posterior, foi solicitado aos alunos que trouxessem para a aula na escola notícias veiculadas em diversos meios de comunicação, à escolha do aluno, sobre a temática da violência no esporte. Muitos não trouxeram, então, como alternativa, foi autorizado que pesquisassem nos seus celulares dentro da sala de aula para realizar a atividade. Muitos alunos não possuíam celulares, alguns sim, mas sem acesso à internet, e a escola não disponibiliza uso do wi-fi, então se organizaram em grupos para utilizar o celular dos colegas. As notícias escolhidas pelos grupos de alunos foram retiradas dos sites UOL, G1, El País e Correio Brasiliense. Todas as notícias escolhidas eram relacionadas à violência no esporte futebol. 
Foi percebido um grande foco no esporte futebol nas discussões; não é de se admirar, pois o futebol, desde muito tempo, é destaque na mídia brasileira. Giglio (2007) fala que o futebol faz parte da vida cotidiana dos brasileiros, onde estudos mostram que a paisagem do campinho de futebol é tão encontrada nos municípios como as igrejas e, dentre as atividades esportivas desenvolvidas nos municípios, o futebol fica no topo da lista. O futebol é visto como uma atividade de lazer de fácil acesso para a maioria da população brasileira, e uma boa parcela dos brasileiros sonham em se tornar jogadores profissionais de futebol devido ao status que a nossa sociedade atribui a eles. $\mathrm{O}$ futebol é o esporte que mais ocupa espaço nos noticiários esportivos e lidera as transmissões ao vivo brasileiras. O futebol acaba transformando a vida do brasileiro, afetando toda a população. Ainda:

\begin{abstract}
Em época de Copa do Mundo as pessoas são dispensadas mais cedo do trabalho e da escola para assistir aos jogos da seleção brasileira. No entanto, esse fato somente acontece com esse evento futebolístico, pois a rotina da cidade segue inalterada e não há mudança no horário laboral quando o país disputa uma Olimpíada (GIGLIO, 2007, p. 35).
\end{abstract}

Ao socializar as notícias sobre violência no esporte, escolhidas pelos alunos, a professora estimulou debates com perguntas, como por exemplo: Qual a sensação de vocês perante esse tipo de notícia? Vocês acham que isso é frequente? Há um padrão? Só no Brasil acontece isso ou em outros países também? Será que essas atitudes de violência são necessárias? É natural esse tipo de comportamento? Entre outros questionamentos.

Para uma análise mais aprofundada das notícias, com a intenção de desenvolver o hábito nos alunos de analisar criticamente as informações recebidas, voltando o olhar sobre as deficiências e as possibilidades desses meios de comunicação contribuírem para a promoção de uma cultura de paz, foi utilizado como base para análise das notícias uma tabela citada no artigo de Cabral e Salhani (2017), comparando o Jornalismo de guerra e o Jornalismo para a paz. 
Figura 1 - Comparações entre o jornalismo para a paz e o jornalismo de guerra

\begin{tabular}{|c|c|}
\hline Jornalismo para a paz & Jomalismo de guerra \\
\hline L. Orientado para a paz/conflito & 1. Orientado para a guerra/violencia \\
\hline $\begin{array}{l}\text { - Explore a formaçáo do confititos: hà partes, otjectivos o } \\
\text { problemas multiplos }\end{array}$ & $\begin{array}{l}\text { - Foca na arena do conflitox hi duas partas e um } \\
\text { obietivo (vencer) }\end{array}$ \\
\hline - Todxs as partec ganham & - Uma parta ganha, a cotra perde \\
\hline $\begin{array}{l}\text { - Espaco e tempo abertos causas e consequéncias em } \\
\text { qualquer lugar, inclusive na história e na cultura } \\
\text { - Apresenta os conflitos com transparáncia }\end{array}$ & $\begin{array}{l}\text { - Espaço s tempo fechados: causas e consequäncias se } \\
\text { restringen a arona, focando em quem atrou a primeira } \\
\text { pedra }\end{array}$ \\
\hline - Da voz a todas as partes, com empatia o entendimento & - Apresenta a guerra de forma obscura'secreta \\
\hline - We confilto e guerra como problemas e foca na & - "Wie contra eles"; voz scmente para "nós" \\
\hline criatividade & - V6́ "eles" como o problema o foca em quem prevalece \\
\hline - Humariza todas as partes, eepecialmente quando hi & na guerra \\
\hline $\begin{array}{l}\text { amamentos } \\
\text { - E proativo: busca a prevencio antes que a vicieincia e }\end{array}$ & $\begin{array}{l}\text { - Desumaniza "eles", especialmente quando há } \\
\text { armamentos }\end{array}$ \\
\hline $\begin{array}{l}\text { guerra ocoram } \\
\text { Foca nos deiton imvisvets daviolineinc tramm. }\end{array}$ & $\begin{array}{l}\text { - É reativo: espera atos violentos para reportar } \\
\text { - Foca mos efottor visiveis da violitincis nümero de }\end{array}$ \\
\hline danos a estrutura e à cultura & mortos, feridos e danos materiais \\
\hline II Orientado nara a verrlade & II. Orientado para a propaganda \\
\hline - Expöe as inverdades de bodas as partes & $\begin{array}{l}\text {-Expòe inverdades sobre "elos" e quida a encotrir as } \\
\text { "nossas" mentiras }\end{array}$ \\
\hline III. Orientado para as pessoas & III. Orientado para as elites \\
\hline $\begin{array}{l}\text { - Foca no sctrimento de todos e dia vaz a mueheres. } \\
\text { crianças, idosos }\end{array}$ & $\begin{array}{l}\text { - Foca no "nosso" sotrimento; tem homens da elite } \\
\text { como porta-vozes }\end{array}$ \\
\hline & N. Orientado para a vitoria \\
\hline N. Orientado para soluçes & Per a vilicha + cossar-fogo \\
\hline - Destaca iniciativas voltadxs para a par, a fim de, & $\begin{array}{l}\text { - Oculta as iniciatvas de par ati que a vitiona ja tenha sido } \\
\text { conquitada }\end{array}$ \\
\hline - Foca na estrutura na culturse em uma sociedade & - Foca em tratados, insthuipies e em una sociedada \\
\hline $\begin{array}{l}\text { pacafica } \\
\text { - Resultado. resoluçäa, reconstrupäa, reconcilaçäo }\end{array}$ & $\begin{array}{l}\text { - Parto para outras guerras e retoma à mesma caso hajam } \\
\text { guesfies pendeales }\end{array}$ \\
\hline
\end{tabular}

Fonte: Cabral e Salhani (2017)

Os grupos de alunos registraram algumas considerações sobre as análises das notícias (Jornalismo para a paz x Jornalismo de guerra):

A notícia está contribuindo a favor da violência, pois não diz o motivo da briga e também não disseram nada que fosse contra a briga. Eles só estão preocupados em saber o que ocorreu e com quem, mas não se importam em dizer o motivo. $\left(8^{\circ} \mathrm{A}\right)$

Nossa notícia fala sobre cultura de guerra, pois foca nos efeitos visiveis da violência: número de mortos, feridos e danos materiais. $\left(8^{\circ} \mathrm{A}\right)$

Jornalismo para guerra, pois ele foca em mostrar as consequências da briga entre os torcedores. $\left(8^{\circ} \mathrm{A}\right)$

"A notícia é voltada ao jornalismo de guerra porque fala sobre o número de mortos, onde ocorreu, o porquê só uma versão foi contada e ficou só nisso". $\left(8^{\circ} \mathrm{B}\right)$

Jornalismo de guerra porque não entrevistou ninguém e só o da paz que tem solução. $\left(8^{\circ} \mathrm{C}\right)$

O jornalista escreveu sobre a cultura da violência/guerra. Foca na arena de conflito, o número de óbitos causados pela violência nas arenas do país. Ele devia ter focado mais na criatividade e na solução do problema. $\left(8^{\circ} \mathrm{C}\right)$ 
Ele apenas aponta os fatos e o que aconteceu naquele momento, colocando mais para o jornalismo de guerra sem colocar a solução para a paz, colocavam quantos feridos e as mortes, o ocorrido, o ano, o dia e o lugar. Não entrevistaram ninguém. $\left(8^{\circ} \mathrm{C}\right)$

Em resumo, foi apontado na roda de conversa que todas as notícias somente focavam em relatar os fatos ocorridos, e muitas vezes só mostravam um lado da história, deixando a desejar um contexto onde há outras versões da história, muitas vezes sem depoimentos de sujeitos participantes ou até mesmo de especialistas, sem apontar as causas dos conflitos e não propondo alternativas de solução. Segundo Cabral e Salhani (2017), não encontramos facilmente em circulação no discurso midiático a temática da cultura de paz, sendo que, por exemplo, as coberturas jornalísticas transbordam de violência porque tem mais impacto e chama mais a atenção do público do que manifestações pela paz, atendendo isso a interesses relacionados ao controle social por alguns grupos da sociedade.

Podemos enxergar na comunicação um meio para atingir os fins voltados para uma cultura de paz. No entanto:

O desafio da comunicação educativa é mostrar as realidades que the preocupam, manifestar suas causas, transmitir os motivos por que considera que devem ser abordadas e fazer chegar suas propostas de mudança. E sempre adotando a emoção necessária, através das possibilidades do discurso, para que os públicos lhe prestem atenção e as incorporem no seu pensamento e na sua atitude. Tudo isso, visando aos interesses coletivos, marcados pelas necessidades públicas e globais. Ou seja, que por fim, utilizará discursos que não serão neutros, mas que nascerão de compromissos que promovam outros compromissos (NOS ALDÁS, 2010, p. 114).

Ainda podemos complementar que:

As características da sociedade atual - marcada por um ritmo vertiginoso de trabalho e um bombardeio constante de mensagens sobre acidentes, agressões, tragédias, ameaças de guerra ou terrorismo - levam o ser humano a buscar, em seus momentos de ócio, estímulos distanciados da densidade de explicações, da denúncia ou da culpabilidade. Esta realidade demanda novas formas de comunicar a necessidade de a sociedade civil abordar determinados problemas, de denunciar as injustiças, ou até de divulgar os aspectos positivos da diversidade e da solidariedade. $\mathrm{O}$ mundo contemporâneo precisa de fórmulas discursivas originais e eficazes para evitar as consequências da desumanização no imaginário cultural (como por exemplo, a abstração da imigração ou a apresentação negativa da diversidade); para conseguir que a sociedade se envolva nas alternativas, que resista a se deixar levar pela apatia, pela indiferença e que, definitivamente, não acabe perdendo sua consciência de cidadania (NOS ALDÁS, 2010, p. 124). 
Nos Aldás (2010) nos mostra a necessidade de se pensar numa comunicação, que seja informativa, mas que também englobe processos de reflexão, que a comunicação seja um meio, um instrumento que sirva para promover reflexões sobre a sociedade em que vivemos, propondo alternativas de transformação para fins de uma sociedade mais humana, mais solidária. Vem a ser relevante uma comunicação onde seu discurso contenha embasamento educativo, baseando seus temas nos alicerces do conflito e também resolução, promovendo um maior envolvimento dos leitores, estimulando processos de conscientização.

\section{Considerações finais}

Há que se considerar que ainda temos muito a caminhar para uma efetivação de uma cultura de paz em nossa sociedade, há muito o que se pensar em como podemos contribuir para uma efetiva disseminação de hábitos e ações que favoreçam processos educativos e comunicacionais voltados para a promoção de uma cultura de paz. Apontamos nesse trabalho um caminho referente a uma educação para uma cultura de paz, utilizando-se de recursos midiáticos e tecnológicos, tendo como base a contribuição de todos e muito diálogo para um maior entendimento de mundo, da nossa realidade, e de como podemos nos orientar rumo a uma transformação em nossa sociedade. Frisamos também a importância de não só a instituição escolar ser responsável por essa conscientização, mas também os demais setores da sociedade em geral, principalmente os meios de comunicação de massa que exercem grande influência no imaginário social, disseminando opiniões e comportamentos, podendo servir como um meio para alavancar fins de violência ou paz. De acordo com Cabral e Salhani (2017), todos os campos do conhecimento podem contribuir para o avanço das investigações sobre a paz, pois o seu caráter é multidisciplinar.

\section{REFERÊNCIAS}

ASSEMBLÉIA GERAL DAS NAÇÕES UNIDAS (AGNU). Resolução 53/243.

A/RES/53/243 de 6 de outubro de 1999. Disponível em:

http://www.comitepaz.org.br/download/Declara\%C3\%A7\%C3\%A3o\%20e\%20Programa\%20 de\%20A\%C3\%A7\%C3\%A3o\%20sobre\%20uma\%20Cultura\%20de\%20Paz\%20$\% 20 O N U$.pdf. Acesso em: 21 jun. 2019.

BETTI, M. (Org.). Educação Física e Mídia: novos olhares, outras práticas. São Paulo: Hucitec, 2003.

CABRAL, R.; SALHANI, J. Jornalismo para a paz: conceitos e reflexões. Revista da Associação Nacional dos Programas de Pós-graduação em Comunicação/E-compós, 
Brasília, v. 20, n. 3, 24 dez. 2017. Disponível em: http://www.e-compos.org.br/ecompos/article/view/1371. Acesso em: 18 jun. 2019. DOI:

https://doi.org/10.30962/ec.v20i3.1371

CONTE, E.; HABOWSKI, A. C.; RIOS, M. B. Ressonâncias das tecnologias digitais na educação. Revista Ibero-Americana de Estudos em Educação, Araraquara, p. 31-45, jan. 2019. ISSN 1982-5587. Disponível em:

https://periodicos.fclar.unesp.br/iberoamericana/article/view/11110/7869. Acesso em 18 abr. 2020. DOI: https://doi.org/10.21723/riaee.v14i1.11110

FISAS, V. Una cultura de paz. In: FISAS, V. Cultura de paz y gestión de conflitos. Barcelona: Icaria/UNESCO, 1998. Disponível em: http://escolapau.uab.cat/img/programas/cultura/una_cpaz.pdf. Acesso em: 18 jun. 2019.

FONTELES, R. C.; GARCÍA, C. C. Cinco minutos de valores humanos em la formación del professorado. Revista Ibero-Americana de Estudos em Educação, Araraquara, v. 6, n. 1, p. 98-105, fev. 2012. ISSN 1982-5587. Disponível em:

https://periodicos.fclar.unesp.br/iberoamericana/article/view/4801/4071. Acesso em: 18 abr. 2020. DOI: https://doi.org/10.21723/riaee.v6i1.4801

FREIRE, P. Educação como prática da liberdade. 24. ed. Rio de Janeiro: Paz e Terra, 2000.

FREIRE, P. Pedagogia do oprimido. 46. ed. Rio de Janeiro: Paz e Terra, 2007.

GALTUNG, J. Violência cultural. Gernika-Lumo: Gernika Gogoratuz, 2003.

GIGLIO, S. S. Futebol: mitos, ídolos e heróis. 2007. 160 f. Dissertação (Mestrado em Educação Física) - Universidade Estadual de Campinas, Campinas, SP, 2007.

GUARESCHI, P. A.; BIZ, O. Mídia, educação e cidadania: tudo o que você deve saber sobre mídia. Petrópolis, RJ: Vozes, 2005.

LIBÂNEO, J. C. As tecnologias da comunicação e informação e a formação de professores. In: VALE, J. M. F. et. al (Orgs). Escola pública e sociedade. São Paulo: E. A. Lucci, 2002. p. 163-169.

MARTÍNEZ GUZMÁN, V. Uma proposta de filosofia para a paz. In: JALALI, V. R. R. (Org.). Estudos para a paz. Aracaju: Criação, 2010. p. 15-30.

MENEZES, M. A. S. A educação para a paz no contexto escolar. In: JALALI, V. R. R. (Org.). Estudos para a paz. Aracaju: Criação, 2010. p. 183-189.

NOS ALDÁS, E. Repensar e reaprender a comunicação para uma cidadania cosmopolita. In: JALALI, V. R. R. (Org.). Estudos para a paz. Aracaju: Criação, 2010. p. 113-127.

PÚBLIO JÚNIOR, C. O docente e o uso das tecnologias no processo de ensinar e aprender. Revista Ibero-Americana de Estudos em Educação, Araraquara, v. 13, n. 3, p. 1092-1105, jul. 2018. ISSN 1982-5587. Disponível em:

https://periodicos.fclar.unesp.br/iberoamericana/article/view/11190/7521. Acesso em: 19 abr. 2020. DOI: https://doi.org/10.21723/riaee.v13.n3.2018.11190 
RABBANI, M. J. Cidadania e a busca pelo reconhecimento nas sociedades modernas. In:

JALALI, V. R. R. (Org.). Estudos para a paz. Aracaju: Criação, 2010. p. 31-54.

SILVA, R. L. O. Resolução de conflitos a partir da escola: uma proposta para a construção da paz. In: JALALI, V. R. R. (Org.). Estudos para a paz. Aracaju: Criação, 2010. p. 169-181.

\section{Como referenciar este artigo}

PATRINHANI, F. G.; AMÉRICO, M. Mídia, cultura de paz e educação física escolar. Revista Ibero-Americana de Estudos em Educação, Araraquara, v. 15, n. 4, p. 1991-2005, out./dez. 2020. e-ISSN: 1982-5587. DOI: https://doi.org/10.21723/riaee.v15i4.13581

Submetido em: $14 / 01 / 2020$

Revisões requeridas em: 28/04/2020

Aprovado em: 18/06/2020

Publicado em: 30/08/2020 